
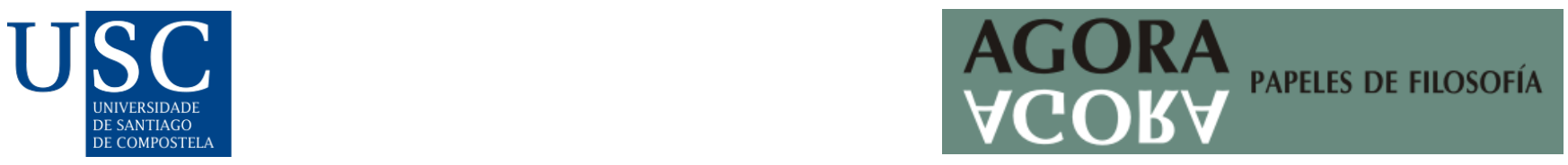

\title{
EL PLURALISMO RELIGIOSO EN EL JOVEN HEGEL. ESPACIOS COMUNES DESDE LOS QUE GENERAR UN DIÁLOGO INTERRELIGIOSO
}

\author{
Andrés Ortigosa ${ }^{1}$ (iD \\ ${ }^{1}$ Universidad de Sevilla, España
}

Recibido: 26/01/2021; Aceptado: 09/03/2021

\section{Resumen}

El pluralismo religioso trata de presentar lugares comunes en los que establecer diálogos entre diferentes religiones sin intención de persuadir. En esta investigación se aborda el pluralismo religioso en los periodos de Tubinga y Berna de Hegel. Esto es, en la filosofía del joven Hegel, periodo en el que se dedicó especialmente a la reflexión sobre la política y la religión. En este periodo, menos estudiado por la academia que su madurez, encontramos que hay al menos tres lugares comunes que pueden facilitar el diálogo interreligioso: el sentimiento, la universalidad ética y la libertad. En esta investigación se presenta estos tres tópicos que Hegel descubre para el diálogo entre diferentes religiones para, finalmente, conectarlos con la discusión cronológicamente posterior sobre el pluralismo religioso.

Palabras clave: Joven Hegel; pluralismo religioso; diálogo interreligioso; libertad

\begin{abstract}
Religious pluralism tries to present common places in which to establish dialogues between different religions without the intention of persuasion. This research deals with religious pluralism in Hegel's Tübingen and Berne periods. That is, in the philosophy of the young Hegel, a period in which he was specially engaged in reflections on politics and religion. In this period, less studied by the academy than his maturity, we find that there are at least three common places that can facilitate interreligious dialogue: sentiment, ethical universality and freedom. This research presents these three topics that Hegel discovers for dialogue between different religions and finally connects them to the chronologically later discussion of religious pluralism.
\end{abstract}

Keywords: Young Hegel; religious pluralism; interreligious dialogue; freedom

\section{INTRODUCCIÓN}

Vivimos en un mundo donde el pluralismo religioso está a la orden del día. Los diversos flujos migratorios, las comunicaciones, y la tolerancia religiosa progresiva de muchos países facilitan que 
este fenómeno sea común. Parte de la riqueza de un país es, precisamente, su diversidad, no solo cultural, sino también religiosa. Pero, aunque hoy se siente con especial intensidad la diversidad religiosa, en realidad se lleva gestando durante siglos, lo que propicia que haya en la actualidad y en el pasado reflexiones filosóficas sobre este tema.

Mi propósito es poner de relieve la concepción del pluralismo religioso en el joven Hegel. Concretamente, en Tubinga y en Berna porque en los escritos de estos periodos creo que hay argumentaciones verdaderamente poderosas para establecer lugares comunes para un diálogo sobre la religión. Por tanto, este estudio no es una exposición sistemática de la filosofía de la religión del joven Hegel. Más bien, lo que se intenta es identificar los puntos en los que el joven Hegel considera lo que llamamos actualmente pluralismo religioso para traerlo al diálogo actual sobre este tema.

Sin embargo, es natural que surja la duda de por qué enfocarlo en el joven $\mathrm{Hegel}^{1}$, y no en el periodo de madurez, que es el pensamiento que suele conocerse de este filósofo. Debo decir que encuentro tres motivos. El primero es que los escritos del joven Hegel son eminentemente escritos sobre religión. Frente a su esplendor en la madurez, llenos de especulación filosófica, los escritos de juventud abordan de manera muy directa la religión, lo que lo vuelve un buen lugar para buscar ideas sobre el diálogo interreligioso. El segundo motivo es que el joven Hegel ha sido un periodo mucho menos estudiado que su madurez. Por eso creo que es considerable investigar sus reflexiones de juventud, pues han sido más desatendidas académicamente. En tercer lugar, creo que el joven Hegel es un gran crítico de la religión en general. Pero también trata de establecer muchos lugares comunes entre unas religiones y otras, que es justo en lo que me quiero centrar. Por eso la filosofía del periodo de juventud de Hegel parece un lugar idóneo para buscar el diálogo interreligioso. En el periodo de madurez es más difícil trazar un pluralismo religioso. Si atendemos a las religiones determinadas (que abarca a la religión de los romanos, la china la hindú, etc.) vemos que para el Hegel de madurez existe una religión verdadera. Todas las religiones anteriores parecen ser una propedéutica de esta verdadera religión. 0 si se prefiere, son condiciones necesarias, pero no suficientes. ${ }^{2}$ Por eso, parece más pertinente trasladarnos al periodo de juventud.

Para hacer esto lo primero que investigo es la idea del pluralismo religioso. Para ello, me nutro de las ideas de Raimon Panikkar, teólogo y filósofo que siempre abordó el tema del diálogo entre las diferentes religiones. Una vez que la noción de diálogo religioso queda establecida como marco teórico, entonces paso a examinar esta idea en el joven Hegel en las dos siguientes secciones. En la tercera sección lo hago en el Fragmento de Tubinga. En este escrito creo que Hegel defiende un núcleo común de las diferentes religiones a través de la afectividad. Pero, como veremos, es un tipo de afectividad muy especial, pues en contra de lo que suele pensarse, esta afectividad religiosa no necesita estar subordinada al entendimiento. En la cuarta sección se investigará Historia de Jesús, y en parte, justificada por su relación con la anterior obra mencionada, en su escrito La positividad de la religión cristiana. Encontramos que Hegel establecerá ideas para un pluralismo religioso desde una órbita kantiana. Esto pasa, en primer lugar, por la autonomía moral del sujeto como lugar común de todas las religiones y, en segundo lugar, por considerar a la religión como una afirmación de la libertad.

Como trataré de remarcar en las conclusiones, creo que las argumentaciones del joven Hegel sobre pluralismo religioso pueden ser de gran utilidad para la actualidad. En un mundo donde el pluralismo religioso es parte de nuestro día a día, reflexionar sobre cómo podemos sentar lugares 
comunes parece que es una tarea necesaria por la que deberíamos abogar, y en el joven Hegel podemos encontrar varias claves para esto.

\section{PLURALISMO RELIGIOSO Y DIÁLOGO}

El pluralismo religioso es inevitable en nuestras sociedades. Con él, también lo es el conflicto. ¿Cómo se inicia el pluralismo religioso? Surge cuando dos o más creyentes de diferentes religiones no pueden solucionar el conflicto religioso entre sí. Es decir, surge sobre todo de la vida práctica en la que no nos encontramos como sujetos aislados, sino como personas en sociedad que se relacionan con otras personas. Es lo que la literatura de la segunda mitad del siglo XX denominó el problema de la alteridad (o también de la otredad).

Panikkar, lo comenta así: «la praxis nos impulsa a tomar postura ante la presencia efectiva del otro, cuando la praxis hace imposible el evitar la mutua interferencia, y cuando el conflicto no puede ser resuelto por el triunfo de una de las partes o un sector de éstas. El pluralismo aparece cuando el conflicto es inevitable». ${ }^{3}$ En nuestra sociedad actual, en la que cada vez es más fácil la comunicación entre los lugares más recónditos del planeta, en que los flujos migratorios y otros eventos son cada vez más comunes, entonces parece que es más inevitable que nunca el pluralismo religioso. Pero, antes de entrar con detalle en las respuestas de Hegel sobre este tema, conviene preguntarnos sobre qué es este fenómeno del pluralismo religioso.

Como el célebre Panikkar cuenta, es precisamente cuando se supera el etnocentrismo que necesitamos abogar por el pluralismo. Entender que no hay una supremacía religiosa, sino una gran cantidad de religiones que pueden dialogar entre sí. De esta manera, comenta que cuando fue a la India a hablar con los teólogos, se dio cuenta de que «entonces se inicia un esfuerzo de integración y uno se da cuenta de que la teología no es una cosa que se aprende de memoria, sino que surge de una experiencia personal en la cual se integran todos los datos». ${ }^{4}$

Como puede observarse, el etnocentrismo religioso encuentra su limitación en el mismo instante en que logra encontrar otras religiones con el mismo lugar común, que es la experiencia. Para una persona religiosa y razonable — dejando aparte por ejemplo a los fanáticos y de otros fundamentalismos religiosos - cuando esto sucede y se asume que una religión no es superior a otra, entonces encontramos un marco de respeto entre todas las religiones. A esto es a lo que se denomina pluralismo religioso.

Cuando el pluralismo religioso se instaura, entonces se pueden tomar dos actitudes. La primera es la de intentar convencer al contrincante en ese diálogo, que no es otro que la persona que no comparte nuestra misma religión. Entendemos que su postura es diferente de la nuestra, la respetamos, pero, aun así, tratamos de convencer a esa persona de la nuestra, es decir, de cambiar sus convicciones. Es lo que desde la retórica clásica se ha llamado diálogo dialéctico, en el que los diferentes oradores exponen sus argumentos con el objetivo de conseguir que los oyentes queden convencidos de sus razones y los apoyen. Sin embargo, frente al diálogo dialéctico, Panikkar observa que se puede tomar otra actitud. Esta sería el diálogo dialogal, que es la práctica de intentar encontrar lugares comunes en los que poder hablar y compartir información, pensamientos y vivencias entre varios creyentes. En este segundo tipo de diálogo lo que se pretende es «conocer en la medida en que somos conocidos y viceversa». ${ }^{5}$ 
Así pues, esta investigación se enmarca como un intento de encontrar esos lugares comunes en los que las personas pertenecientes a diversas religiones son capaces de mantener un diálogo dialogal auspiciados por las reflexiones del joven Hegel. ${ }^{6}$ A continuación, pasaré a exponer cómo en algunos escritos de juventud de Hegel podemos encontrar estos lugares comunes que facilitarían en nuestra actualidad el diálogo entre las diversas religiones.

\section{EL PLURALISMO RELIGIOSO EN EL PERIODO DE TUBINGA: LA CRÍTICA DEL JOVEN HEGEL AL ETNOCENTRISMO}

No se pude realizar una exposición exhaustiva del Fragmento de Tubinga debido a que, entonces abordaríamos muchos temas, muy variados, y eso nos descentraría. Por ello, mi propósito es pasar a comentar los fragmentos en las que el joven Hegel se pronuncia sobre las diferentes religiones.

En el periodo de Tubinga, el joven Hegel considera que la religión debe ser asunto del corazón. Esta expresión, «asunto del corazón» tiene el papel de reivindicar el valor de la subjetividad humana en su contexto. Frente a la religión que aprendió en el seminario de Tubinga, cuando estudiaba teología junto a Hölderlin y Schelling, que se basaba en la racionalidad y el dogmatismo en las costumbres, el joven Hegel quiere reivindicar algo olvidado: la afectividad en la religión. ${ }^{7}$

En el tiempo de Hegel, y en cierto sentido en el panorama actual, el papel del sentimiento en las diferentes religiones ha sido apartado e infravalorado. Parece que la religión y el sentimiento fuesen contradictorios. Es en este clima en el que el joven Hegel quiere reivindicar justamente lo contrario: lo esencial de las religiones es el sentimiento. Esto no quiere decir que no haya racionalidad, costumbres, tradiciones, etc. Las hay, pero la base sobre la que todas ellas se construyen es por un sentimiento común. Es decir, no se puede separar a las tradiciones religiosas de su vivencia sentimental.

Haciendo alusión al Natán del filósofo popular, Lessing, el joven Hegel señala que: «Allí donde el corazón no habla más alto que el entendimiento (...) es que ese corazón ya no sirve para mucho y el amor no habita en él». ${ }^{8}$ Esta idea es presentada como un cambio de «la plenitud y la afectividad de la fe por fríos conocimientos y palabras vacías». ${ }^{9}$ El conocimiento que nos produce el entendimiento en las religiones, es importante. Pero no tanto como el sentimiento. El conocimiento sobre, por ejemplo, las características de Dios es un conocimiento inferior al sentimiento de la religión. Lo primero es poner a Dios bajo un microscopio. Lo segundo es experimentar, vivir y sentir la religión plenamente. Esto es lo que nos guiará a la tolerancia y el respeto mutuo entre las religiones. ${ }^{10}$

De resultas, el joven Hegel está planteando que, en las religiones, las entidades afectivas pueden ser suficientes, es decir, no hay necesidad de subordinarlas al entendimiento. Son suficientes porque no están separadas del psiquismo humano. No son unas entidades distintas de nosotros. Pero, desde la óptica del joven Hegel, lo que no hace falta es subyugarlas al entendimiento, sino que su papel en el psiquismo humano es distinto. Está en la propia vivencia. Por eso la religión tiene que apelar al corazón, y no encerrarse solamente en la racionalidad. ${ }^{11}$

Fenomenológicamente, podríamos decir que, por ejemplo, cuando un creyente se siente agradecido por algún suceso en su vida (como el nacimiento de un hijo o una hija), el sentimiento de gratitud para con su dios, la manera en que tiene de vivir en ese momento su religión, no opera mediante el entendimiento, aunque esté inmiscuido en el psiquismo. El entendimiento, en cualquier 
caso, serviría para explicar posteriormente la conducta, pero no es aplicable en ese momento concreto. Y es justamente en nuestras vivencias cuando cualquier creyente considero que podría darle la razón a Hegel: la religión es vivida en ese momento, y solo después es pensada. Pero en ese momento, los afectos no están subordinados al entendimiento. Sencillamente son entidades suficientemente fuertes, sólidas e hilvanadas en el psiquismo humano, que no necesitan subyugarse al entendimiento en ese preciso instante.

Pues bien, estas entidades afectivas en las que nos encontramos todos los seres humanos, estas vivencias religiosas que provocan una afectividad son, para el joven Hegel, el terreno desde la que se puede erigir cualquier religión. Es el lugar común de las diferentes religiones. Propiamente, el joven Hegel lo ejemplifica del siguiente modo: «quien llama a su Jehová Júpiter o Brahma y es un verdadero adorador de Dios, testimonia su gratitud y su sacrificio de un modo tan inocente como el verdadero cristiano». ${ }^{12}$ Así las cosas, todas las religiones tienen en común ese mismo suelo, ese mismo humus. La afectividad es el lugar común y originario de cualquier religión. Este planteamiento nos permite reflexionar sobre el etnocentrismo religioso.

El etnocentrismo queda instantáneamente eliminado para el joven Hegel. Nadie puede tener derecho a presuponer su superioridad cultural, o religiosa, con los demás. Por eso Hegel, en la cita anterior alude al «verdadero cristiano». Aunque suene a perogrullada, conviene caer en la cuenta de que «el verdadero cristiano» es, justamente, el que no es «falso cristiano». En un ambiente como el seminario de Tubinga, de orientación protestante, donde se enseña teología, es probable que la idea del verdadero y falso cristiano jugase un papel importante. Y lo que el joven Hegel está diciendo es, justamente, lo contrario: cualquier otra persona que viva plenamente su religión -ya sea musulmana, católica o judía - es capaz de dar un testimonio de gratitud y sacrificio igual de potente que el del mejor cristiano. Es decir, lo que el joven Hegel está trazando es una auténtica cruzada al etnocentrismo religioso. ${ }^{13}$

Atendamos a que no lo disputa en el terreno del entendimiento. Sino que, el joven Hegel, muy originalmente, sigue otra estrategia argumentativa. Como decimos, no desacredita al etnocentrismo religioso mediante la razón teórica. No hay una crítica al etnocentrismo, por ejemplo, con argumentos históricos. Tampoco con argumentos meramente lógicos. La racionalidad queda relegada a un papel secundario ahora mismo. Siguiendo al joven Hegel lo que verdaderamente desacredita al etnocentrismo, lo que realmente nos hace darnos cuenta de que no somos superiores por nuestras creencias, es justamente que nuestra afectividad y manera de vivir sentimentalmente la religión es tan poderosa como la de cualquier otra persona. Todas las vivencias religioso-afectivas pueden tener el mismo grado de intensidad para todas las personas. Y es entendible que, entonces, desde una posición humilde - es decir, dejando fuera del análisis los sentimientos religiosos de los fanáticos, por ejemplo- todas las personas razonables opten por considerar a nuestras vivencias religiosas igualmente válidas.

Esto entronca perfectamente con el planteamiento sobre el joven Hegel de Dilthey. Para este autor, conocido hermeneuta y crítico del etnocentrismo, el joven Hegel en su proyecto de madurez tratará de racionalizar la vida. Sin embargo, en su juventud tiene un proyecto totalmente distinto. El joven Hegel expone la vida y las vivencias de manera no-conceptualizadas. Según Dilthey, en este periodo el joven Hegel estaría intentando esclarecer cómo surgen las religiones de los diferentes pueblos, y encuentra su fundamento en el sentimiento. Como el propio Dilthey señala, «en esta concepción se manifiesta el pensamiento historicista del joven filósofo orientado a la comunidad». ${ }^{14}$ 
Esto es importante. No es el sentimiento de un individuo aislado, sino que el joven Hegel se preocupa por un sentimiento popular, de una comunidad entera.

Creo que la consideración de Dilthey es en parte cierta. Sin embargo, Dilthey, quizá por ser un hermeneuta, dio en este punto un papel fundacional a la historia, y no rinde cuentas suficientemente con lo que implica el sentimiento como génesis de las diferentes religiones, como origen de las diferentes comunidades en sus escritos sobre el joven Hegel. Sin embargo, el sentimiento ha quedado constituido por el joven Hegel como el punto común y punto de inicio de cualquier religión. Lo verdaderamente importante no es el planteamiento histórico, sino que es justamente ese sentir que experimentamos cada uno de los sujetos de nuestra religión. Por eso, pensar que una religión es superior a otra es una idea descabellada: todas las religiones tienen la misma validez precisamente porque todas tienen un mismo origen en nuestras vivencias.

En conclusión, podemos decir que el joven Hegel encuentra que el origen de todas las religiones es el sentimiento. Es un origen común. De esta manera, para poder establecer un diálogo dialogal tal y como proponía Panikkar, en el que interesarme por el otro, por la persona que me es ajena, que es de otra religión, parece que un punto por el que se puede empezar a construir este diálogo es en la semejanza de los orígenes. No obstante, la filosofía de la religión del joven Hegel no se queda solo en este hallazgo, sino que quedan al menos otros dos lugares comunes a todas las religiones que permitirán el diálogo dialogal.

\section{PLURALISMO RELIGIOSO EN EL PERIODO DE BERNA: UNIVERSALIDAD Y AFIRMACIÓN DE LA LIBERTAD}

Normalmente se suele comprender a Hegel en el periodo de Berna como un férreo defensor del kantismo. Esto es totalmente cierto. Es más, su relectura de los evangelios y su relato sobre la vida de Jesús han sido objeto de interés de investigadores, que han analizado sus reinterpretaciones bíblicas, ${ }^{15}$ que en este periodo están especialmente bajo el influjo de Kant. Sin embargo, creo que Hegel va un poco más allá que Kant. No es que tenga una línea de pensamiento totalmente distinta a la del filósofo de Königsberg, sino que en algunos aspectos la desarrolla llegando más lejos que Kant, como trataré de exponer.

Así pues, lo primero que examinaré es la idea de la universalidad moral del imperativo categórico. Pero el enfoque que pretendo adoptar es poco tradicional. Se trata de exponer cómo el imperativo categórico formulado desde el joven Hegel encaja en la cuestión del pluralismo religioso. El segundo punto que quiero tratar es, en el mismo escrito de Hegel, lo que creo que es una extensión que va algo más allá que Kant, aunque por su mismo camino. En esta extensión considero que Hegel descubre la relación entre la religión con la libertad, lo que, como trataré de expresar, engarza perfectamente con el pluralismo religioso.

\subsection{La universalidad moral de todas las religiones}

En esta sección pretendo dar paso a uno de los escritos de Hegel en Berna. En este periodo hay dos grandes escritos. Uno es su obra Historia de Jesús. En él Hegel narra e interpreta la vida de Jesús de Nazaret, pero lo hace desde unas coordenadas morales kantianas. Así, Hegel reescribe la historia de Jesús y sus actos como si fuese un kantiano —o más propiamente, el primer kantiano de 
la historia. Esta obra nos interesa especialmente desde una doble perspectiva. Por una parte, es una obra de filosofía moral en la que el joven Hegel trata de explicar el imperativo categórico a través de la figura de Jesús. De este modo, Jesús es un «héroe moral» que defiende la autonomía racional y la libertad. ${ }^{16}$ Desde una segunda óptica, Historia de Jesús es también una obra en la que hay una filosofía de la religión porque el imperativo categórico, como moral, termina siendo el núcleo del cristianismo. Es decir, al reducirse la religión a moral, entonces es también una obra de filosofía de la religión. Curiosamente, en esta obra, via imperativo categórico, creo que podemos encontrar ideas para el pluralismo religioso.

El otro escrito, que enlaza perfectamente con el primero, es La positividad de la religión cristiana. En este Hegel plantea cómo el cristianismo, desde las vivencias y la moral, ha ido evolucionando hasta adquirir su corpus legal. Dicho de otro modo, es un estudio sobre la positivización del cristianismo, abordando también cuestiones como si la religión debe estar unida al Estado o no.

Conviene poner de sobre aviso al lector que, en este caso, el pluralismo religioso para el joven Hegel es visto desde el kantismo. Así, la antigua argumentación del Fragmento de Tubinga en la que el sentimiento era el principio - en su doble acepción, es decir, como inicio, pero también como principialidad - de la religión está ya lejos. No la contradice, pero tampoco aparece. En este caso, la reconciliación entre las diferentes religiones irá acompañada de argumentaciones mucho más racionales, dejando absolutamente de lado el papel del sentimiento como consecuencia de su acercamiento a la filosofía de Kant. Pero constituye otra visión posible del pluralismo religioso.

Para situar al lector en el punto que nos interesa de esta investigación, debe saber que en la obra Historia de Jesús Hegel considera que la razón es la facultad distintiva del ser humano. A través de ella, todo lo natural adquiere un carácter superior. Por ejemplo, los impulsos naturales son controlados gracias a la razón. A este control que ejercemos sobre nuestra naturaleza es a lo que popularmente denominamos moral.

Si bien el joven Hegel defiende que la razón ennoblece a los impulsos, rigiéndolos, controlándolos, esto nos lleva a que el ser humano tiene la capacidad de ser libre de sus impulsos. Esto no es algo que se encuentre en el escrito, sino una consecuencia. ${ }^{17}$ Pero claro, es una consecuencia porque para el joven Hegel, para que haya moralidad tiene que haber necesariamente libertad. Solamente si entendemos al ser humano como un ser libre podemos juzgar hasta qué punto ha actuado en una situación correcta o incorrectamente.

Pues bien, ante la evidencia de la libertad del ser humano, aparece el siguiente problema: ¿cómo podemos actuar moralmente? El joven Hegel responde desde el kantismo, probablemente, imbuido por el clima intelectual de su época. Lo innovador es, en este caso, que logra hacerlo uniéndolo con una relectura bastante propositiva de la vida de Jesús. Así, a continuación, cito parte de un discurso de Jesús en esta obra de Hegel: «actuad de acuerdo con una máxima tal que podáis querer que, como ley universal entre los hombres, valga también para vosotros». ${ }^{18}$ Esta idea es perfectamente kantiana. Kant, había formulado su imperativo categórico de la siguiente manera: «El imperativo categórico es, pues, único, y es como sigue: obra sólo según una máxima tal que puedas querer al mismo tiempo que se torne ley universal». ${ }^{19}$ Es lo mismo que está diciendo Hegel. De hecho, ambas oraciones son casi idénticas no solo lingüísticamente, sino también en su contenido, que es el establecimiento del imperativo categórico. ¿Qué significa que haya una defensa del imperativo categórico por parte del joven Hegel?

Que haya un imperativo categórico que dictamina cómo debemos comportarnos todos los seres humanos significa que tiene pretensiones de universalidad. Por esto mismo, Hegel continúa 
exactamente la anterior cita aludiendo que «ésta es la ley fundamental de la moralidad, el contenido de todas las legislaciones y de los libros sagrados de todos los pueblos». ${ }^{20}$ Esto que señala el joven Hegel es, desde su óptica, el punto común que tienen todas las religiones del mundo. Absolutamente todas, en el fondo, lo que proponen es que las acciones de los individuos sean de tal calidad moral, que puedan ser consideradas como universalmente válidas. Por este motivo, si bien la sección anterior veíamos que para el joven Hegel todas las religiones tienen un mismo origen en el sentimiento, lo cierto es que ahora lo que plantea es que todas tienen un mismo objetivo. Todas las religiones pretenden generar buenas personas de conducta intachable sin importar nuestro sexo, género, cultura, raza, ni tan siquiera, nuestra religión. Personas cuyas acciones puedan ser universalmente aceptadas por todos nosotros. Esto es, personas que siguen el imperativo categórico en realidad. Eso es el núcleo común, como objetivo en este caso, de todas las religiones para el joven Hegel, que no duda en poner estas palabras en los labios de Jesús.

Fijémonos en que, desde la racionalidad práctica, el imperativo categórico funciona como una fórmula ética. Entiendo por fórmula una regla que, dependiendo de sus valores, da un resultado distinto. De este modo, si en el imperativo categórico pregunto si debería robar, tengo que pensar si verdaderamente podría considerar que robar sea una ley universal. En este caso, obviamente el robo no debe ser una ley universal, y, por tanto, yo como individuo no debo robar. Así, actúo de tal manera en que «no robar» es una ley que puede ser válida universalmente. El joven Hegel pone varios ejemplos en su escrito del imperativo categórico. Por ejemplo, en uno se plantea si se debe respetar a nuestros enemigos. Hegel, que en este momento busca como individuo la ley universal, concluye lo siguiente: «respetad la humanidad también en vuestros enemigos; en caso de que no los podáis amar, desead el bien de quienes os maldicen y haced el bien a quienes os odian». ${ }^{21}$ Si nos fijamos, al aplicar el imperativo categórico, nadie debe desearle el mal a nadie, sino desearles el bien a todas las personas, incluso si son sus enemigos. Esto es producto de la aplicación de la fórmula ética del imperativo categórico. Pero asumir que hay una fórmula ética por encima de cualquier determinación del ser humano es algo que va más allá de nuestra religión incluso: es una unión (moral) en el origen de los propios seres humanos. Esto volvería a posibilitar un diálogo dialogal, es decir, un acercamiento a conocer a las otras personas diferentes a nuestra religión precisamente porque compartiríamos un mismo núcleo. 0 , como mínimo, se compartiría que el objetivo de cualquier religión es generar a buenas personas - aunque siguiendo al joven Hegel para esto habría que seguir el imperativo categórico. ${ }^{22}$

Sin embargo, es imposible no ver cierto reduccionismo en este escrito de Hegel. Siguiendo a Kant, llega a afirmar el absurdo del culto. El culto, ya sea el judío, el musulmán o el cristiano, es para él, un sinsentido porque lo verdaderamente importante no es la festividad o el culto que se realiza en cada religión, sino que lo relevante es la ley moral. Desde la óptica del joven Hegel, el culto es un tema absolutamente secundario para generar a buenas personas. Por eso, al ser tema secundario, llega a proclamar que «llegará el día en que ya no celebraréis culto divino alguno». ${ }^{23}$ Esta limitación de Hegel es, en realidad, una limitación que hereda de la forma de ver la religión que tenía Kant. ${ }^{24}$ El filósofo de Königsberg en su obra La religión dentro de los límites de la mera razón, había propuesto el mismo tipo de universalidad en todas las religiones. Y también había expuesto que, debido a la importancia que adquiere la moral - que es el imperativo categórico- para todas las religiones, cualquier culto era inútil. Casi un vestigio. Para Kant, a Dios en realidad lo único que le puede interesar es que nos comportemos moralmente, y no si le guardamos culto. 
Si nos detenemos en lo expuesto hasta ahora, podemos encontrar que la moral es fruto de la razón. El imperativo categórico funciona mediante el empleo de la racionalidad humana para su vida práctica. Por eso Kant hablaría de la «religión racional», es decir, el núcleo de la religión es la racionalidad, que en último término nos lleva a aplicar el imperativo categórico. Por este motivo, para Kant, como él mismo redactó, «solo hay una (verdadera) Religión; pero puede haber múltiples modos de creencia». ${ }^{25}$ Da igual el tipo de creencia que tengamos. No importa si somos musulmanes, católicos, protestantes, judíos, o cualquier otra religión. Todas ellas son solamente creencias, y lo que es verdaderamente religión es la religión racional.

Esto provoca que en Kant podamos observar cierta teleología de las diferentes creencias que adopta el joven Hegel. Para Kant, y en consecuencia para el joven Hegel, llegará el día en que todas las religiones del mundo hagan a un lado sus diferencias y, sencillamente, se limiten a compartir que lo verdaderamente importante es ser personas buenas, esto es, que actúan bajo el imperativo categórico. Esto sería una fusión futura de las religiones. Pero mientras tanto, el pluralismo religioso aparece como un lugar al que transitar antes de llegar a esta unión de religiones en una sola religión. Mas, insisto, en que, lo cierto es que sigue habiendo un núcleo para todas las religiones, un lugar común en el que establecer un diálogo dialogal como ya se ha explicado.

\subsection{Autoridad y libertad: Ia religión como afirmación de la libertad}

Un poco más adelante, en Historia de Jesús, Hegel tomará como tema de estudio la autoridad y la religión via moral. La moral de la razón, es decir, el imperativo categórico, debe ser una moral autónoma como propuso Kant. Pero Hegel señala que esto es gracias al yo. El yo es lo que se pone de relieve con la razón. Y gracias a la razón, nuestro yo consigue ser imparcial a la hora de juzgar una conducta. Es decir, la razón consigue ser un tribunal imparcial, lo que posibilita aplicar el imperativo categórico de manera en que esa universalidad no se confunde con la conveniencia de cada individuo, es decir, con el egoísmo. Hegel lo pone en boca de Jesús: «este yo se manifiesta como razón, cuya legislación no depende de ninguna otra cosa y a la que ninguna autoridad en la tierra o en los cielos puede imponer otra medida del juzgar. Esto que yo enseño no lo hago ni por ocurrencias mías ni por propiedad mía; no exijo que nadie tenga que aceptar esto fiándose de mi autoridad, pues no busco mi gloria». ${ }^{26}$

El joven Hegel está tan seguro de esta idea que, como la cita misma señala, no tiene que atenderse a esto porque sea Jesús el que lo dice. En absoluto. Lo puede comprender cualquier persona con independencia de su creencia religiosa. Cuando algo es verdadero por sí mismo, no tiene que apoyarse únicamente en la autoridad, sino que se torna comprensible para cualquier sujeto que lo reflexione. Además, conviene recordar que Jesús es Dios, por tanto, fijémonos en que el joven Hegel está diciendo que nadie tiene que obedecer a Dios por ser solo una autoridad absoluta, sino que todo lo que Dios puede proponer es perfectamente entendible desde la razón. Todos los seres humanos tienen de esta manera la capacidad de conocer el mensaje de Dios. Todas las personas son un yo, que como hemos visto, es lo mismo que decir que todas las personas tienen la facultad de la razón. Por tanto, el imperativo categórico ostenta el máximo rango de accesibilidad para todas las personas por el mero hecho de ser agentes racionales. Por eso no importa la religión en la que se crea: baste con ser persona.

Pero esto ha abierto la veda a que, lo que se obedece por autoridad, es ilegítimo, pues la conducta moral debe ser autónoma, es decir, determinada desde el yo para el yo. Es en este aspecto que 
el joven Hegel critica la actitud que los fariseos tomaron con Jesús. Este episodio se refiere a que los fariseos tenían la prohibición de trabajar en sábado. Era el día sagrado en el que no se podría trabajar para ellos. Pero Hegel, por medio de Jesús, dice «el hombre es más que un templo; es el hombre, y no un lugar determinado, el que santifica esas acciones o las hace impías; el sábado está hecho por causa del hombre, y no el hombre por causa del sábado, pues el hombre es también señor del sábado». ${ }^{27}$ En este aspecto, lo que es lo sagrado queda reducido a mera autoridad, que nada tiene que decir sobre la autonomía moral. Así, todo lo que consideramos sagrado descansa en que hay una autoridad que apunta que eso debe ser entendido como sagrado, pero no porque lo sea verdaderamente.

Es el ser humano el que constituye, por ejemplo, a través de la tradición, lo que debe ser sagrado o no. Es obra del hombre. Y que los lugares o los días sagrados sigan viéndose como tal, es solo y exclusivamente debido a que existe una autoridad que así lo dictamina, y no porque sea producto de la autonomía moral y la razón. Por tanto, lo sagrado, ya sean lugares, días o cualquier cosa, no es sagrado porque el objeto albergue algún tipo de sacralidad. La sacralidad es puesta por el ser humano, y mantenida por la autoridad.

Pues bien, es en este contexto en el que podemos ver una clara influencia kantiana, otra vez, en la que lo heterónomo es desprestigiado por mor de lo autónomo. Justamente es en la autonomía donde Hegel encuentra verdaderamente la libertad. Así las cosas, Jesús es en el escrito de Hegel un destructor de prejuicios contrarios a la razón. Todo lo que no es autonomía del sujeto es relegado, abandonado. Debe ser apartado. Pero porque es en la autonomía donde reside la libertad. Por eso, Jesús dice en este escrito que «yo me atengo tan sólo a la genuina voz de mi corazón y de mi conciencia; quien obedece a ésta rectamente, es iluminado por su verdad; hacer caso de esta luz es lo único que exijo de mis discípulos. Esta ley interior es una ley de la libertad, ley a la que el hombre se somete libremente como dada por sí mismo». ${ }^{28}$

Situada las coordenadas de la libertad y su vinculación con la razón y la moral, el joven Hegel apunta que no se debe temer cuando una autoridad nos pide explicaciones de nuestro comportamiento siempre y cuando hayamos seguido al imperativo categórico. La razón ejerce mediante el imperativo categórico juicios ético universalmente válidos, por tanto, el que obedece al imperativo categórico nada debe temer, pues nadie puede reprochar que su conducta no haya sido moral.

Sin embargo, el joven Hegel vislumbra un problema serio. Si la libertad reside en todas las personas, entonces ¿se puede obligar a alguien a pertenecer a una religión? ¿Debe existir una autoridad capaz de obligar a que ingresemos en alguna religión?

Para responder a estas dudas, el joven Hegel se sitúa en el origen del cristianismo. Al inicio, ingresar en una comunidad eclesial era algo absolutamente voluntario. Es solamente con el paso del tiempo y el afianzamiento del cristianismo - como podríamos decir de cualquier religión en su contexto cultural y geográfico- que todas las personas ingresarían en una comunidad eclesial como deber. ${ }^{29}$ Esto viene precisamente porque a lo largo de la historia la religión llega a las instituciones, concretamente, al Estado. Durante largos periodos de la humanidad — como parte de la Edad Media y Edad Moderna-, el Estado y a religión permanecen en perpetua unión.

¿Qué ocurre si la religión se entremezcla con el Estado? Pues que todo crimen civil pasa a ser también un crimen eclesial. De ahí que haya una lista tan número de los castigos canónicos. ${ }^{30}$ De este modo, el joven Hegel creo que está describiendo un proceso institucional de positivización. Es decir, no es solamente que las religiones tengan su propia manera de percibir el mundo, y de esa 
manera cada una considere legítimo o ilegítimo ciertas acciones. No es solo que los castigos de cada religión se diferencien. Lo que verdaderamente ocurre es que hay un empoderamiento de la religión a través de su unión con el Estado. Esto deja muy poco espacio para la libertad religiosa, pues si alguien naciese en un país cuyo Estado está íntimamente unido a la religión, entonces se le obliga a profesar una fe particular desde el momento de su nacimiento. No hay libertad de elección, sino un determinismo religioso-estatal. Es un positivismo religioso impuesto. ${ }^{31}$ En él, no hay libertad, sino que la libertad justamente radica en el respeto a la diferencia, que es algo que se ha defendido en general en el diálogo interreligioso: «la libertad religiosa no se hace efectiva desde el imperio de la ley, sino desde la toma de conciencia de la diversidad, diferencia, disidencia propia de las sociedades democráticas». ${ }^{32}$ El joven Hegel, como puede verse, está en unas coordenadas muy cercanas a la cita anterior para proponer la libertad religiosa.

Esta idea guía al joven Hegel a una segunda conclusión, que aparece un poco más tarde en $L a$ positividad de la religión cristiana. Esta conclusión es que el Estado, si es un estado civil, «no debería adherirse a fe alguna: tampoco lo deberían hacer sus legisladores y administradores en cuanto tales» ${ }^{33}$ porque se corre el riesgo de que entonces el Estado se vuelva intolerante con las personas que no profesan su misma creencia. En otros términos, podemos afirmar que el joven teólogo plantea que para que verdaderamente pueda existir pluralidad religiosa, entonces los diferentes Estados no pueden adherirse a ninguna fe en particular. Deben mantenerse neutros. Por tanto, otro punto común que tendrían las diferentes religiones es que, para Hegel, todas deberían tener el mismo trato por parte del Estado para que no se imposibilite el ejercicio de libertad religiosa.

También Hegel considera que la religión es una materia que debe mantenerse al margen de la enseñanza. Hegel conocía sobradamente este tema, pues acababa de terminar sus estudios de teología en el seminario de Tubinga. Para él, que sigue muy de cerca los ideales de la Ilustración de la alta cultura y el refinamiento, del Bildung, la educación es fundamental pues «los hombres, al nacer, no traen consigo solamente el derecho de subsistir físicamente, entran al mundo también con el derecho de desarrollar sus facultades, de llegar a ser personas». ${ }^{34}$ Sin embargo, si la religión intercede en la educación entonces el desarrollo de nuestras capacidades está orientado a cumplir con unos deberes impuestos, heterónomos, no elegidos por nosotros mismos. Esto es para Hegel un hecho condicionante, no uno determinante porque al final en el ser humano siempre reside la libertad. Así, si la educación recibida y creencias religiosas de un país no concuerdan con nuestra manera de pensar, siempre cabe decidir si abandonar ese país y sus leyes e ir a otro más afín. A fin de cuentas, como él mismo señala, «nunca puede suprimir la posibilidad de la elección libre». ${ }^{35}$

Por supuesto, desde esta óptica la religión debe ser un acto de elección libre. Obligar a alguien a convertirse en una religión es pura heteronomía, es decir, una imposición por fuerza de la autoridad. Eso es justo lo que hay que evitar. En su lugar, hay que considerar la libertad de elección, de conciencia, y especialmente, la libertad de moral que debe obedecer únicamente a la autonomía del sujeto. Por eso, si al entendernos como sujetos, es decir, como seres libres, elegimos formar parte de una creencia religiosa o de otra, entonces lo que estamos haciendo es un acto de afirmación de nuestra libertad porque no somos de una religión por imposición, sino porque libremente se ha elegido pertenecer a ella.

Esto es un sentido de la libertad semejante a cuando Leonardo Polo expresó que al tratar la inagotabilidad de las personas, hemos de darnos cuenta de los límites de la biología y la sociología frente a la libertad humana. La persona «justamente por no proceder enteramente de sus padres, cada persona humana es un novum, en el sentido más estricto de la palabra: una criatura para cuya 
existencia no basta la línea generativa de orden natural, histórica». ${ }^{36}$ Precisamente, el ser humano es una criatura que no está limitada solamente a su biología y sociología, sino que es más que eso: es un ser libre. Y en esto creo que concuerdan Polo, Kant, y el joven Hegel: la dimensión de la libertad humana desborda a su condición biológica. Esto es la base antropológica que subyace a la propuesta de Hegel en realidad. Sin embargo, en este caso, el joven Hegel lo ha reenfocado hacia la religión - aunque parta de esta misma base del ser humano como ser de libertad- considerando que la religión no es enemiga de la libertad. Es, justamente, al contrario. Incluso el acto de elegir libremente nuestra religión es un acto que manifiesta la imparable libertad del ser humano.

Así las cosas, esto es un tercer lugar común en las religiones. Todas las religiones deben ser entendidas como afirmaciones de la libertad de las personas, es decir, como una enorme manifestación de la libertad humana (siempre que no sean religiones positivas e impuestas, pues eso sería heteronomía). Esto es un punto común que tendrían todas las religiones para el joven Hegel. Al contrario, el ser humano debe ser tratado siempre como lo que es: un ser autónomo. Esto es extensible a todas las religiones, por lo que todas ellas deberían ser vistas como afirmaciones de la libertad, lo que a su vez permitiría un acercamiento entre los diferentes creyentes que facilitaría el diálogo interreligioso por compartir ni más ni menos que la idea de libertad humana.

\section{CONCLUSIONES: TRES IDEAS PARA UN PLURALISMO RELIGIOSO EN EL SIGLO XXI}

A lo largo de este escrito hemos podido ver que el joven Hegel establece tres lugares para el pluralismo religioso. Por una parte, encontramos su escrito Fragmento de Tubinga. En él, Hegel llega a considerar a parte de la subjetividad humana como suelo firme sobre la que se erige cualquier religión. Concretamente, los afectos y el sentimiento tienen para él la misma validez en cualquier creyente con independencia de su religión. Todos tienen el mismo derecho a vivir y experimentar sus sentimientos religiosos porque, en último término, el sentimiento es el origen de toda religión. Pero es sentimiento que emana de la propia vivencia. En consecuencia, las posturas etnocéntricas religiosas, así como también las religiosas radicales, como el fanatismo, quedan totalmente descartadas e injustificadas. Ningún creyente es superior a otro por su creencia porque todos comparten en un grado de intensidad sus vivencias religiosas. Esto nos permitiría cierto «pluralismo inclusivo» ${ }^{37}$ en el que se buscaría fomentar la comunicación en la diversidad de las diferentes religiones.

Esto creo que es una argumentación que merecería ser rescatada en nuestro siglo XXI. Como ha apuntado Antonio de Diego, ${ }^{38}$ en la actualidad existen diversos grupos religiosos que, bajo la apariencia de ideología y religión, en realidad tratan de ser impositivos con sus creencias, llegando a extremos indeseables. Sin embargo, creo que, si lo miramos desde la óptica del joven Hegel, lo cierto es que son un tipo de etnocentrismo que puede ser desarticulado desde el sentimiento. Que la afectividad y el sentimiento sean el punto común e inicio de todas las religiones es, como se ha defendido, una enorme crítica a las conductas etnocentristas porque de una manera muy intuitiva e inmediata nos permite ver que no puede existir supremacía de una religión frente a otra (al menos en este ámbito).

Por otra parte, como segunda consideración, encontramos una argumentación muy distinta del joven Hegel en su periodo de Berna en el escrito Historia de Jesús. En él, hemos visto que Hegel sigue 
muy cercanamente a Kant. Tanto lo sigue, que la única verdadera religión es la religión racional, es decir, el actuar correctamente siguiendo el imperativo categórico. Siguiendo a Kant, esto nos permitía comprender que solamente eso es la verdadera religión, y el resto son solamente creencias, hasta tal punto, que incluso el culto quedaría obsoleto con el paso del tiempo por ser innecesario en la religión racional. Como se ha señalado, esto creo que es una limitación grave que establece Hegel por seguir tan cercanamente a Kant. No es que no haya libertad de culto, sino que piensan que el culto no tiene sentido.

Eso nos hace plantearnos, de cara a futuras investigaciones, la diferencia entre el joven Hegel en Tubinga y el joven Hegel en Berna, pues si bien en el primer periodo no hay nada explícito al respecto, sí que parece que el culto podría estar muy relacionado con los sentimientos que emanan de un creyente. Por ejemplo, con el agradecimiento o la hospitalidad.

No obstante, debemos considerar que es una forma de concebir cierta unión en el pluralismo religioso. Una gran diferencia a unos creyentes de otros es el culto y sus costumbres. Pero lo que los une es que todas las religiones quieren generar a buenas personas, guiadas por la moral. Por eso parece que, aunque con un enfoque algo limitado sobre el culto, es rescatable la idea de que todas las religiones tienen el mismo objetivo. Podemos o no estar de acuerdo con la propuesta de Hegel, que es conseguir la unión de todas las religiones en una sola llamada religión racional, bajo el imperativo categórico kantiano, pero lo que parece indudable es que el joven Hegel ha encontrado un punto común con el resto de las religiones que es distinto al sentimiento. Si la afectividad y el sentimiento eran el origen común de todas las religiones, lo cierto es que generar a buenas personas es el objetivo común. Por tanto, queda establecido un segundo punto que amplía nuestro horizonte para establecer un diálogo interreligioso.

En tercer y último lugar, la religión es entendida como un acto donde se manifiesta la libertad del ser humano. Ciertamente, como se ha visto, el joven Hegel considera que el Estado y la religión deben estar separados, igual que la religión y la educación. Pero fijémonos en que lo hace precisamente para que nadie se vea condicionado a tener que pertenecer a una religión que no ha elegido de corazón. Es decir, el verdadero creyente es el que elige libre y conscientemente su fe. Y esto es otro punto común que deberían compartir todas las religiones: asumir la libertad de elección religiosa y bajo ningún precepto tratar de ser impositivas. Esto es, respetar la autonomía del ser humano y renegar de la heteronomía. En consecuencia, todas las religiones pueden ser entendidas como manifestaciones de la libertad del ser humano, o lo que es lo mismo, la religión es considerada como una afirmación de la libertad. 0 siguiendo las ideas de Kant tratadas en este escrito, la libertad es autonomía y, por consiguiente, autodeterminación. Esto es un núcleo teorético que parecen compartir el joven Hegel y Kant. Así, que todos los creyentes hayan elegido su religión libremente es otro punto común que podrían tener todas las religiones y que nos permite un diálogo dialogal en el sentido en que se vio anteriormente.

De esta manera, creo que se puede concluir que tanto el origen, que es el sentimiento, como el objetivo, que es generar a buenas personas, así como la afirmación de la libertad, son tres puntos comunes de cualquier religión. Al menos, en la filosofía del joven Hegel. Y me aventuro a proponer que, quizá sean buenos lugares comunes para comenzar un diálogo interreligioso que respete el pluralismo tan característico de nuestro siglo XXI en futuros proyectos e investigaciones. 


\section{Bibliografía}

De Diego González, A. (2020): Populismo Islámico. Cómo se ha secuestrado la espiritualidad musulmana, Córdoba: Editorial Almuzara.

Dilthey, W. (2013): Hegel y el idealismo, México: FCE, 2013, 3ํㅡㄹ ed.

Gómez, C. M. (2018) «El desafío de la verdad al diálogo interreligioso». Theologica Xaveriana, vol .68, nํ185, pp. 1-23.

Harris, H. S. (1972): Hegel's Development. Toward the Sunlight 1770-1801, Oxford: Oxford University Press. Hegel, G.W.F. (1978): Escritos de juventud, México: FCE, trad. José María Ripalda.

Hegel, G.W.F. (1981): Historia de Jesús, Madrid: Taurus, trad. S. González.

Hegel, G.W.F. (1994) «Fragmento de Tubinga»», Revista de filosofía, 11, trad. María del Carmen Paredes, pp. 139-176.

Hegel, G.W.F. (2017): Enciclopedia de las ciencias filosóficas, edición bilingüe, Madrid: Abada Editores, trad. Ramón Valls Plana.

Hegel, G.W.F. (2018): Filosofía de la religión, Madrid: Trotta, trad. Ricardo Ferrara.

Herrero, M., (2018) «Variaciones hegelianas de la crítica bíblica ilustrada: el espíritu frente a la letra», Scripta Theologica, vol. 50, 2, pp. 275-302.

Kant, I. (1991): La religión dentro de los límites de la mera razón, Madrid: Alianza Editorial.

Kant, I. (2007): Fundamentación de la metafísica de las costumbres, Puerto Rico: San Juan.

Lukács, G. (1970): El joven Hegel y los problemas de la sociedad capitalista, Barcelona: Ediciones Grijalbo.

Samonà, L. (2007) «L'accoglienza dell'altro l'universale. La prospettiva di un pluralismo inclusivo», en $L a$ filosofia di fronte allá pluralità delle religioni, Roma: Aracne, pp. 47-59.

Padial, J. J. (2013) «Los hábitos y la emergencia de la subjetividad, la autoconciencia y la cultura según Hegel», en Annuario Filosófico XXIX, pp. 139-151.

Paredes, M. C. (2002) «Convergencia de las religiones en Hegel y Lessing», en Álvarez, M., (ed.), Pluralidad y sentido de las religiones, Salamanca: Universidad de Salamanca, pp. 73-90.

Paredes, M. C. (2015) «El joven Hegel», en Amengual, G. (ed.) Guía Comares de Hegel, Granada: Editorial Comares, pp. 1-32.

Panikkar, R. (1985) «La vocación humana es fundamentalmente religiosa», Anthropos, no5, 54, pp. 16-21.

Panikkar, R. (1990): Sobre el diálogo intercultural, Salamanca: Editorial San Esteban.

Panikkar, R. (2006): Paz e interculturalidad. Una reflexión filosófica, Barcelona: Herder.

Polo, L. (1995) «El hombre como hijo», en Cruz, J. (ed.) Metafísica de la familia, Pamplona: Eunsa, pp. 317-325

Ripalda, J. M. (1978), «Introducción», en Hegel, G. W. F. Escritos de juventud, FCE: Madrid, pp. 9-32.

Roa, J. A. (1999). «Las grandes religiones: su encuentro y su aporte para la paz». Theologica Xaveriana, $n^{\circ}$ 131 , pp. 313-320.

Rousseau, J. J. (2008): Emilio o sobre la educación, Madrid: Edaf.

Notas

1 En este escrito tomo el periodo de juventud de Hegel hasta 1801. A partir de esa fecha sus escritos serán ampliamente filosóficos sobre diversos temas. Sin embargo, hasta ese año sus escritos son eminentemente religiosos, o si se prefiere, sobre filosofía de la religión (y moral), sin tener intención de generar un sistema 
filosófico propiamente (Cfr. J. M. Ripalda, «Introducción», en G. W. F. Hegel, Escritos de juventud, FCE: Madrid, 1978, p. 11).

Hegel deja ver esto nítidamente, y lo expresa así: «En la religión determinada como tal o en la religión finita no presenciamos sino determinaciones inferiores del espíritu o de la religión, todavía no tenemos la religión de la verdad absoluta. Pero para que la religión llegue a su verdad absoluta (...), este itinerario es una condición. Estas religiones determinadas son etapas determinadas de la conciencia, del saber acerca de Dios. Son condiciones necesarias para el surgimiento de la religión verdadera, para la conciencia verdadera del espíritu» (G.W.F. Hegel, Filosofía de la religión, Madrid: Trotta, 2018, pp. 108-109).

3 R. Panikkar, Sobre el diálogo intercultural, Salamanca: Editorial San Esteban, 1990, pp. 20-21.

4 R. Panikkar, «La vocación humana es fundamentalmente religiosa», Anthropos, 53, 54, (1985), p. 20.

5 R. Panikkar, Paz e interculturalidad. Una reflexión filosófica, Barcelona: Herder, 2006, pp. 52-57.

6 Desde esta óptica, no debe confundirse el lector. No se va a abordar el tema de la verdad en las diferentes religiones, sino los lugares comunes que nos posibiliten establecer un diálogo. Para un estudio sobre la verdad y el dialogo interreligioso, véase: C. M. Gómez, «El desafío de la verdad al diálogo interreligioso». Theologica Xaveriana, 68, 185, (2018), pp. 1-23.

$7 \quad$ Una de las lecturas de Hegel en el periodo de Tubinga, en este aspecto, fue principalmente la de Rousseau. Aquí podríamos verse una influencia notoria, pues el filósofo francés había planteado que la religión es, ante todo, sentir, más que un corpus dogmático. Rousseau lo señala así: «Yo sirvo a Dios en la simplicidad de mi corazón. No pretendo saber sino lo que importa a mi conducta. En cuanto a los dogmas que no influyen ni sobre las acciones ni sobre la moral, y por los que tantas gentes se atormentan, no me tomo trabajo alguno» (J. J. Rousseau, Emilio o sobre la educación, Madrid: Edaf, 2008, p. 356).

8 G. W.F. Hegel, «Fragmento de Tubinga», Revista de filosofía, 11, (1994) p. 157.

9 Ibid., p. 156.

10 En el seminario de Tubinga, junto a sus lecturas de Rousseau, una de las lecturas que más impactaron al joven Hegel fue la de Natán el sabio, obra del filósofo popular, Lessing. En esta obra de teatro hay un llamamiento a la tolerancia religiosa. El propio Hegel, en su Fragmento citará a Lessing, así pues, es muy probable que, como ha apuntado María del Carmen Paredes, esta visión del joven Hegel sobre la tolerancia religiosa sea un contagio intelectual de Lessing, y que no por casualidad, haga alusión a Natán el sabio. Para un estudio sobre la influencia de Lessing en el joven Hegel, véase: M. C. Paredes, «Convergencia de las religiones en Hegel y Lessing», en M. Álvarez (ed.), Pluralidad y sentido de las religiones, Salamanca: Universidad de Salamanca, 2002, pp. 73-90.

11 Cfr. M. C. Paredes, «El joven Hegel», en G. Amengual (ed.) Guía Comares de Hegel, Granada: Editorial Comares, 2015, p. 5.

12 Hegel, «Fragmento de Tubinga», p. 156.

13 Esto es así, pero hay que advertir al lector que, en su madurez, una vez más, Hegel cambiará de parecer. Como se dijo en la nota 2, en la madurez Hegel identificará en el futuro una religión verdadera, que es el cristianismo. Exponer los motivos que le hacen transitar desde la postura de juventud a la de madurez, considerando finalmente que hay una religión verdadera es un asunto complejo que no puede resumirse en una sencilla nota al pie, y es un problema en el que, actualmente, me encuentro trabajando.

14 W. Dilthey, Hegel y el idealismo, $3^{\text {a }}$ ed., México: FCE, 2013, pp. 21-22.

15 Para un buen análisis sobre esto, véase: M. Herrero, «Variaciones hegelianas de la crítica bíblica ilustrada: el espíritu frente a la letra», Scripta Theologica, vol 50, 2, (2018), pp. 275-302.

16 Cfr. H. S. Harris, Hegel's Development. Toward the Sunlight 1770-1801, Oxford: Oxford University Press, 1972, p. 207.

17 En su etapa de madurez, sin embargo, Hegel sí que lo contemplará. Concretamente, es el hábito lo que nos libera de los impulsos naturales y de quedar reducidos solamente a ellos, brindándonos la libertad. Para esto, véase los parágrafos concretos, G.W.F. Hegel, Enciclopedia de las ciencias filosóficas, Madrid: Abada Editores, 2017, §406 y §406N; para un estudio sobre la emergencia de la libertad a través de los hábitos en Hegel, véase: J. J. Padial, «Los hábitos y la emergencia de la subjetividad, la autoconciencia y la cultura según Hegel», en Annuario Filosófico XXIX, (2013), pp. 139-151.

18 G.W.F. Hegel, Historia de Jesús, Madrid: Taurus, 1981, p. 40.

19 I. Kant, Fundamentación de la metafísica de las costumbres, Puerto Rico: San Juan, 2007, p. 35.

20 Hegel, Historia de Jesús, p. 40.

21 Ibid., p. 37. 
22 En este punto Hegel está viendo en Jesús una religión de la libertad y la autonomía que tiene como base la educación moral de las personas. Con ello, efectivamente, está siguiendo a Kant. Quizá también la idea de la religión civil de Rousseau en su Contrato social, y de Schiller La educación estética de los hombres. Sin embargo, dejo esto solamente como un apunte debido a que la extensión no me permitiría desarrollar este punto con toda la exactitud necesaria.

23 Hegel, Historia de Jesús, p. 33.

24 Me refiero a esto como limitación debido a que ni Kant ni el joven Hegel (en este momento) son capaces de ver a la religión más allá de la moral. La religión se reduce a moral. Está acotada a los límites de la razón. De suyo, entonces el culto o la plegaria, por ejemplo, dejan de tener valor para la religión porque son acciones que se alejan de lo verdaderamente fundamental de la religión, que es actuar mediante el imperativo categórico. Esto es una consecuencia debido a que, al reducir la religión a la moral, todo lo que no está directamente relacionado con la moral queda fuera de la verdadera religión. Además, me gustaría poner en conocimiento del lector que, aunque en este periodo el joven Hegel rehúse del culto como elemento de la religión, posteriormente probablemente desde Jena - su concepción sobre la religión va alejándose de la visión kantiana. Esto es tan así que en sus Lecciones sobre filosofía de la religión Hegel dedica un apartado entero al culto dándole un papel fundamental. Llega a afirmar que: «en el culto, de un lado está Dios y del otro estoy yo, y la determinación es reunirme con Dios, saberme en Dios y saber a Dios en mí. El culto consiste en procurarse este goce supremo y absoluto» (Hegel, Filosofía de la religión, p. 101). Si bien no obvio estas ideas posteriores, sí que, insisto, en este escrito me estoy centrando solo en un punto concreto de su obra.

25 I. Kant, La religión dentro de los límites de la mera razón, Madrid: Alianza Editorial, 1991, p. 109.

26 Hegel, Historia de Jesús, p. 43.

27 Ibid., p. 44.

28 Ibid., p. 53.

29 Ibid., p. 102.

30 Ibíd., p. 103.

31 Ciertamente, el positivismo en el joven Hegel es una idea de opresión. Comparto con Lukács que «para el joven Hegel, la religión positiva del cristianismo es una columna del despotismo y de la opresión, mientras que las antiguas religiones no-positivas fueron las religiones de la libertad y de la dignidad del hombre. Su renovación es, según las ideas del joven Hegel, un objetivo revolucionario ante cuya realización está puesta la humanidad de su época» (G. Lukács, El joven Hegel y los problemas de la sociedad capitalista, Barcelona: Ediciones Grijalbo, 1970, p. 49).

32 J. A. Roa, «Las grandes religiones: su encuentro y su aporte para la paz». Theologica Xaveriana, 131, (1999), p. 314 .

33 Hegel, «La positividad de la religión cristiana», en Escritos de juventud, México: FCE, 1978, p. 109.

34 Ibid., p. 111.

35 Ídem.

36 L. Polo, «El hombre como hijo», en J. Cruz (ed.) Metafísica de la familia, Pamplona: Eunsa, 1995, p. 323.

37 Sobre la noción de «pluralismo inclusivo» véase: L. Samonà, «L'accoglienza dell'altro l'universale. La prospettiva di un pluralismo inclusivo», en La filosofia di fronte allá pluralità delle religioni, Roma: Aracne, 2007, pp. 47-59.

38 Cfr. A. De Diego, Populismo Islámico. Cómo se ha secuestrado la espiritualidad musulmana, Córdoba: Editorial Almuzara, 2020. 